2020 Global Marketing Conference at Seoul Proceedings: 468-472 (November 2020)

https://doi.org/10.15444/GMC2020.04.06.04

\title{
VIRTUAL SUPERMARKET SETTING: EXPLORING ANTECEDENTS OF EMOTIONS AND PURCHASE INTENTIONS
}

\author{
Sandra Maria Correia Loureiro, Instituto Universitário de Lisboa (ISCTE-IUL) and \\ Business Research Unit (BRU-IUL), Portugal ${ }^{1}$ \\ Carolina Correia, Instituto Universitário de Lisboa (ISCTE-IUL), Portugal \\ João Guerreiro, Instituto Universitário de Lisboa (ISCTE-IUL) and Business Research \\ Unit (BRU-IUL), Portugal
}

\begin{abstract}
Virtual Reality is based on three key characteristics: immersion, interactivity (Boyd \& Koles, 2018). Firstly, when exposed to a virtual environment, the individual experiences the sense of immersion or presence within that environment. The user feels like being there and escaping or becoming isolated from the real world. Beside immersion, VR provides a very dynamic environment (Loureiro et al., 2019), which is important to create consumer involvement. Hence, the current study explores antecedents of emotions and purchase intention in virtual supermarket setting
\end{abstract}

Keywords: emotions, purchase intention, virtual reality, mental imagery, product involvement, presence, virtual supermarket setting

\section{Hypotheses}

In the current study we explore three antecedents of emotions and purchase intention: mental imagery, product involvement and presence. According to Miller, Hadjimarcou and Miciak (2000), mental imagery is an activation of perceptual knowledge stored in a long-term memory and related to a personal experience. Imagery can be evoked by different types of sensory stimulus: tactile, visual, auditory, olfactory or gustatory. This dimension is called modality (Miller, Hadjimarcou, \& Miciak, 2000). Analysing all Mental Imagery characteristics, it is believed in literature that there is a relationship between mental imagery and consumer behavioural intentions (Yoo \& Kim, 2014), that is emotional states and purchase intentions. Therefore, the following hypotheses are formulated:

H1: Mental imagery is positively associated to Purchase Intention

$\mathrm{H} 2$ : Mental imagery is positively associated to Emotions

Product involvement reflects the amount of interest, attention, excitement and motivation of the consumer toward a product (Porral, Vega, \& Mangin, 2018).

So, it is important to understand how to communicate with products with different levels of involvement, because it influences the way customers want to engage with the brands (Porral, Vega, \& Mangin, 2018). Based on this assumption, it is expected that:

H3: Product involvement is positively associated to Purchase Intention

H4: Product involvement is positively associated to Emotions

\footnotetext{
${ }^{1}$ sandramloureiro@netcabo.pt
} 
The feeling of presence brought out by the virtual reality stimulus usually creates a highly involvement with the store atmosphere (Boyd \& Koles, 2018). People can experience the feeling of escaping and telepresence without moving (Kerrebroeck, Brengman, \& Willems, 2017) and influence their behaviour. Based on this the following hypothesis arise:

H5: Presence is positively associated to Purchase intention

H6: Presence is positively associated to Emotions

\section{Methodology}

A quasi-experimental between-subjects design was implemented to test the proposed model. The quasi-experimental manipulation comprised a virtual grocery store, using VR. A quantitative approach was followed using a questionnaire to get data to test the model. The questionnaire was fulfilled after the participants visualize the scenario through VR.

The respondents are regular shoppers who were selected to test a virtual shopping. A virtual scenario was created where the participant experienced a virtual supermarket. The scenario displayed the product assortment, prices and promotions. Participants were requested to wear Oculus Rift, which includes an appropriate oculus to emerge in a virtual world and two motion sensors that detect the movement. Besides, a computer with the software to design the virtual scenario was used. The virtual supermarket was based on an existing shelf layout and real brands in order to resemble the physical experience. The laundry care category was chosen, specifically, HDD - Hard Duty Detergent - and FFI - Fabric Finishers. It is important to refer that to ensure maximum fidelity and allow participants to do the correct comparison, the virtual planogram was based on an existing shelf layout and real brands (Pizzi et al, 2019). Furthermore, the point of sales environment was reproduced, such as shelves, floor and lighting.

\section{Results}

Using the guideline proposed by Hair et al. (2010), the analysis was conducted on two levels: the first-order constructs level and second-order construct level (through PLS). The latter correspond to mental imagery with four factors: vividness, quantity, valence and modality. After analysing the measurement model, convergent and discriminant validity, the structured model is appraisal.

Concerning the established hypotheses, not all paths coefficients were found significant. Table 1 shows the results for each hypothesis. In fact, at a significant level $\mathrm{p}<0.05(\mathrm{t}>1.96)$, hypothesis H1, H2, H3, H5 and H6 are fully supported, only H4 is excluded.

Table 1. Structural Results

\begin{tabular}{lllll}
\hline & $\begin{array}{l}\text { Coefficient } \\
\text { Beta }\end{array}$ & $\begin{array}{l}\text { Standard } \\
\text { Deviation } \\
(\text { STDEV })\end{array}$ & $\begin{array}{c}\text { T Statistics } \\
(\mid \mathrm{O} / \text { STDEV })\end{array}$ & $\begin{array}{l}\mathrm{P} \\
\text { Values }\end{array}$ \\
\hline Menth & 0.307 & 0.096 & 3.203 & 0.001 \\
Mental imagery -> P.Intention & 0.611 & 0.083 & 7.349 & 0.000 \\
P.Involvement -> P.Intention & 0.203 & 0.070 & 2.918 & 0.004 \\
P.Involvement -> Emotions & 0.029 & 0.060 & 0.492 & 0.623 \\
Presence -> P.Intention & 0.491 & 0.069 & 7.149 & 0.000 \\
Presence -> Emotions & 0.191 & 0.058 & 3.271 & 0.001 \\
\hline
\end{tabular}




\begin{tabular}{lll}
\hline Construct & $\mathbf{Q}^{2}$ & $\mathbf{R}^{2}$ \\
\hline Purchase intention & 0.344 & 0.615 \\
Emotions & 0.373 & 0.557 \\
\hline
\end{tabular}

\section{Conclusions and implications}

There are different ways to stimulate mental imagery and the dimensions behave differently depending on the type of the stimuli. Bogicevic et al. (2019) claim that in this new and technologic marketing world, VR can be a significant stimulus. The results show that mental imagery leads to a purchase intention $(\beta=0.307)$, the positive relationship means that, when in the shopping experiences, and images are evoked to our mind, we tend to be more propitious to buy the product. Thus, mental imagery explains the purchase intention variable and $\mathrm{H} 1$ is supported. Concerning the emotions, the results show that there is a relationship between both $(\beta=0.611)$, which means that, when in the shopping experiences and images are evoked to our mind, the emotional reactions to the stimulus are positive and agreeable. Thus, mental imagery explains the emotions variable and $\mathrm{H} 2$ is supported. It is crucial to highlight that the positive effect of mental imagery in emotion is the strongest direct effect of whole hypotheses, pointing out the crucial role that mental imagery may play in the emotions generated. Actually, this result is already expected, having in mind the findings in literature review. Emotional responses occur when our cognitive sense is stimulated (Miller, Hadjimarcou, \& Miciak, 2000) and according mental imagery definition, this is exactly what happens when the mental images come to our mind.

The product involvement is not the same for all consumers, besides each consumer has a different level of involvement depending on the product we are talking about. The level of involvement will determinate the consumer attitude towards the product. Researchers consider that brands should approach differently the audience according the level of involvement. This is where VR has an important role. According to Cowan \& Ketron (2019) the use of VR, as marketing tool, does not impact likewise for products with different degrees of involvement. In fact, using VR enhances the engagement and communication with customers who are highly involved leading to a product purchase.

The results show that product involvement leads to a purchase decision $(\beta=$ 0.203 ), the positive relationship means that, when in the shopping experiences, and consumer who is highly involved with the product/brand, tends to be more propitious to buy the product. Thus, product involvement explains the purchase intention variable and $\mathrm{H} 3$ is supported. It can be explained due to the category chosen for this study - laundry care. This type of category includes products with high involvement level. Consumers of this category mostly look for the maximum information possible, such as benefits, prices, environmental issues, among others... and tend to compare between the different brands which is the best option that will fulfil their needs. The variable product involvement presents a mean of 4.54 , meaning that even not totally involved, the sample shows a positive level.

The results show that product involvement does not have significance or influence on emotions. In other words, regardless the level of involvement, in this context, neither positive nor negative emotions are stimulated. Thus, product involvement does not explain the emotions variable and $\mathrm{H} 4$ is not supported.

The results also show that presence leads to a purchase decision $(\beta=0.491)$, the positive relationship means that, when the consumers feels physical present in a virtual world, tends to be more propitious to buy the product. Thus, presence explains the purchase intention variable and $\mathrm{H} 5$ is supported. Concerning to the impact of 
presence on emotions, as expected, the relationship is significant and positive $(\beta=$ 0.191). This means that, in fact, the interactivity and immersion experienced on virtual supermarket enhances the emotions generated. Thus, presence explains the emotion variable and H5 is supported. It is crucial to highlight that the positive effect of presence in emotion was the weakness direct effect of whole model, in other words the role that presence may play in the emotions is not the most important in the whole model.

\section{Managerial implications}

The present study brings a very relevant and meaningful conclusions which can have impact on marketing field. The findings highlight the importance of the atmospheric conditions for the overall shopping experience in a specific market. More precisely, the impact of a virtual environment in all customer journey, until the purchase decision. In order to create a greater experience with a virtual store, managers should study deeply the market where they are inserted and above all the type of consumer and their shopping behaviour. As a matter of a fact, VR still be a very new tool that people are not used to and it must be applied in marketing step by step. On the one hand, consumers need to be educated for this new shift from traditional to innovative marketing. On the other hand, companies need to take the best part of it and surely create the best atmosphere condition to lead positive emotions and finalizing with a purchase decision. How more involved is the consumer with the product, the more he needs to be engaged with the brand. So, creating the appropriated atmosphere, where the consumer feels immersive and part of the process is a key driver to his satisfaction and increase the purchase intention, and as demonstrated here, VR is a good effect on it.

To sum up, this study comes to emphasize the importance of creating the right atmosphere for a better shopping experience. Marketers must provide a personalized shopping experience given that the different variables that influence the shopper's behaviour.

\section{Limitations and future research}

In spite of the contribute of this study, the results and conclusions should be interpreted according with some specific limitation. The main constraint of the method regards to the data collection. Firstly, the sampled used is not representative since 108 participants are not enough to understand behaviours. Besides few men were able to participate because it is not easy find men that are used to shop laundry products or know the category. A more extensive and diversified sample could lead to different results. For future researches, a larger sample must be considered.

In addition, it would be interesting to consider doing the experience with participants right after leaving a physical supermarket and compare both shopping experiences. Actually, going person to person with all material to perform the test made it difficult to get more people and the time collecting data was longer and delayed all the process. Another limitation on this study is the use of the virtual reality program. Due to the inexperience of using it, the scenario was not perfectly similar with a true supermarket. Moreover, other scenarios should be interesting to study, addressed to other markets and understand if the relationship between variables would be modified. To expand the model behind complement, other variables should be integrated, such as satisfaction or recommendation. 


\section{References (more references upon request)}

Bogicevic, V., Seo, S., Kandampully, J. A., Liu, S. Q., \& Rudd, N. A. (2019). Virtual reality presence as a preamble of tourism experience: the role of mental imagery. Tourism Management, 74, 55-64.

Boyd , D. E., \& Koles, B. (20189. Virtual reality and its impact on b2b marketing: a value-in-use perspective. Journal of Business Research , 100, 1-8.

Cowan, K., \& Ketron, S. (2019). A dual model of product involvement for effective virtul reality: the roles of imagination, co-creation, telepresence, and interectivity. Journal of Business Research, 100, 483-492.

Hair, J. F., Black, W. C., Babin, B. J., \& Anderson, R. E. (2010). Multivariate Data Analysis. Harlow: Pearson.

Kerrebroeck, H. V., Brengman, M., \& Willems, K. (2017). Escaping the crowd: an experimental study on the impact of a virtual reality experience in a shopping mall. Computers in Human Behaviour, 77,437-450.

Loureiro, S.M.C., Guerreiro, J., Eloy, S., Langaro, D., \& Panchapakesan, P. (2019). Understanding the use of Virtual Reality in Marketing: A text mining-based review, Journal of Business Research, 100, 514-530 doi:10.1016/j.jbusres.2018.10.055

Miller, D. W., Hadjimarcou, J., \& Miciak, A. (2000). A scale for measuring advertisement - evoked mental imagery. Journal of Marketing Communication, $6(1), 1-20$. 